\title{
Modifications of neurotoxin-based animal models of the non-motor complications in Parkinson's disease in terms of drug development
}

\author{
Magdalena Kurnik-Łucka*, Andrzej Bugajski and Krzysztof Gil \\ Department of Pathophysiology, Jagiellonian University Medical College, Kraków, Poland
}

\begin{abstract}
The aim of the study was to search for the new animal models of the non-motor symptoms in Parkinson's disease, especially in terms of drug development. Up-todate, development of the new drugs for Parkinson's disease that aim to stop or slow down the disease progression is unlikely due to the lack of models that truly reflect the widespread and progressive pathology of the illness. Similarly, little progress has been made in moving into other pharmacological areas for the treatment.
\end{abstract}

\section{Introduction}

Next year, there will be the 200th anniversary of the publication of James Parkinson's monograph entitled "An essay on the Shaking Palsy" but still, there is no cure for this progressive disease [1]. The sporadic Parkinson's disease (PD) affects all races equally, with slight male predomination, and estrogen replacement therapy was associated with delayed age of the onset of PD [2,3]. The clinical manifestations consist of motor symptoms such as resting tremor, hypokinesia, rigidity, postural instability as well as less obvious, yet burdensome, non-motor complications including olfactory, gastrointestinal, thermoregulatory and genitourinary dysfunction, sleep disturbances, anxiety, fatigue and oral cavity problems [4-9]. Non-motor symptoms in Parkinson's disease appear throughout the course of the disease. According to many experts in the field, non-motor features remain under-recognised, under-researched, and thus, under-treated $[10,11]$.

From the neuropathological point of view, PD is defined by the continuous formation of immunoreactive inclusion bodies, which develop only in susceptible neuronal types within the central and peripheral (including the enteric part) nervous systems [12-14]. These lesions are called "Lewy pathology" and tend to play a key role in the pathogenesis of PD are not limited to dopaminergic neurons of the substantia nigra but also occurs in glutamatergic [12-18], noradrenergic, serotonergic, histaminergic, and cholinergic neurons [19]. Thus, during the past decade, PD has become recognised as a multi-systemic disorder [12,19-22]. Recent findings indicate that the mechanisms of neurons' degeneration and death should be linked to mitochondrial dysfunction, oxidative stress, inflammation and apoptosis [24,25]. And fore-mostly, PD is a result of complex interactions between environmental and genetic factors and thus cannot be studied using simplified in vitro models [26,27].

The aim of the study was to search for novel animal models of the non-motor symptoms closely related to early and prodromal stage of Parkinson's disease, especially in terms of drug development.

\section{Literature search}

A search of relevant terms on PubMed and EBSCO databases was conducted in November 2016 using a combination of key words (Parkinson disease, animal model, neurotoxin) and references of publications of interest. These papers (written in English language only) were further limited due to the primary focus of this review (early phase, early stage, presymptomatic, prodromal, non-motor) and thoroughly reviewed. Additional, significant articles in the field were found in a less formal manner and were used for comparison and inspiration throughout. The majority of papers were published during the past decade.

\section{The classical neurotoxins applied in animal models of Parkinson's disease}

An ideal animal model of disease is described by the presence of behavioural signs and pathology that resemble the disease, including the time course of its progressive nature. The closer the similarity of a model is to $\mathrm{PD}$, the higher the predictive validity for clinical efficacy. Modelling of PD is limited by the lack of complete knowledge about the disease [28]. Sporadic Parkinson's disease is a widespread human disease that has never been reported in non-human vertebrates, which might partially explain the difficulties in the translation of findings from the animal studies into clinically effective treatments, with the exception of the deep brain stimulation which was tested in the MPTPtreated monkeys $[29,30]$. Still, animal models contribute extensively

Correspondence to: Magdalena Kurnik-Łucka $\mathrm{PhD}$, Mpharm, Department of Pathophysiology, Jagiellonian University Medical College, Czysta 18 Street, 31-121 Krakow, Poland, Tel: + 4812 6333947; Fax: + 4812 6329056; E-mail: magdalena.kurnik@uj.edu.pl

Key words: animal models, neurotoxins, Early Parkinson's disease, Non-motor symptoms, Antiparkinsonian drug development

Received: November 29, 2016; Accepted: December 22, 2016; Published: December 26, 2016 
to our understanding of the pathophysiology of this complex and debilitating disease, which consists of an early non-symptomatic period, followed by a prodromal phase, often characterised by olfactory dysfunction, autonomic failure, sleep, and mood disturbances [31-39]. The non-motor features of PD can appear decades before the onset of the motor symptoms and are a challenge to the clinical management of the disease [10,40-42]. The prodromal phase transitions into a phase that is accompanied by the classical motor symptoms and subsequently, impaired cognitive functioning. The duration and characteristics of each phase are hugely variable among patients and might even interfere with the proper diagnosis $[12,43]$. Thus, the "perfect" PD model should reproduce: the progressive evolution of the neuronal damage, the presence of cytoplasmatic inclusions (so called Lewy-like pathology) in both autonomic and central nervous system, the cell loss in the substantia nigra, as well as typical non-motor symptoms followed by the motor ones, and finally be responsive to the already available therapeutics [31].

In terms of animal species, rodent models of PD present the advantage that rats and mice are widely available, have high reproductive rates, require reduced living space, simple feeding and drinking schedules, however diverse susceptibility to neurotoxins exists between those species because of distinct metabolic and enzymatic pathways. The main disadvantage of the animal models of PD is the difference from the human metabolism of toxins and the difference between brain size and complexity of brain functions between rodents and humans, which limits the immediate translation of the experimental results to the clinic. Non-human primate models might bridge the gap and should be considered for testing any novel compounds with antiparkinsonian potential [28].

So far, animal models have been of two major types: toxin-related and genetic models. The usefulness of neurotoxins for modelling especially non-motor complications in PD is limited by the fact that many of these symptoms are at least partially independent of dopamine. Most of the non-motor symptoms do not correlate with the stage of motor deficits and precede the development of the motor symptoms by many years before the permanent loss of dopaminergic neurons in the basal ganglia can be observed $[7,8,35,44-46]$. The most widely used toxins are MPTP, 6-OHDA, paraquat, reserpine as well as rotenone, and have been extensively reviewed in the literature $[24,26-29,31,35,38,46-$ 57]. Less common model substances include tetrahydroisoquinoline derivatives (such as salsolinol, for example) or a fungicide - maneb [31,49,52-58]. Regarding the molecular mechanisms of cell death, the toxin-based models have emphasised oxidative stress, mitochondrial dysfunction, apoptosis and microglial activation as key players in PDrelated neurodegeneration. However, one of the main drawbacks of these exogenous neurotoxins is that all induce a rapid and extensive neurodegeneration in animals which is, unfortunately, contradictory to the natural progression of the disease in human [53]. These models were proved excellent to model motor symptoms seen in PD but so far, their ability to mimic non-motor symptoms seems to be rather limited.

\section{Modifications of the classical neurotoxin-based animal models of the non-motor complications in Parkinson's disease}

Up-to-date, development of the next generation drugs for PD that aim to stop or slow down the disease progression is unlikely due to the lack of PD models that truly reflect the widespread and progressive pathology of the illness and its complexity. Similarly, little progress has been made in moving into other pharmacological areas for the treatment of PD. There is no doubt that the availability of experimental animal models of PD has hugely altered dopaminergic drug treatment of the motor signs of the PD as well as improved the prevention and reversal of drug related side effects that emerge during the disease progression [59].

An extensive pharmacokinetic, pharmacodynamic and pathophysiological data is required to establish an entirely new animal model of a disease. Thus, it is much easier to modify existing experimental models that are known to form the hallmarks of the PD process, and indeed, such attempts have been undertaken. The most promising attempts may be classified into the following categories: 1) neurotoxin-based models with improved protocols, mostly in terms of prolonged delivery or additional routes of administration; 2) administration of well-studied neurotoxins to genetically modified animals; 3) models of dopamine and L-DOPA-related neurotoxicity.

MPTP intoxication was proved to cause parkinsonism in human and therefore is the most greatly studied neurotoxin in PD-related models. The administration of MPTP directly into the substantia nigra of male Wistar rats caused a partial loss of dopaminergic neurons, depletion of striatal dopamine and up-regulation of the pro-inflammatory enzyme cyclooxygenase- 2 resulting in sensorial, memory and motor deficits with temporary impairment [60-65]. Reksidler et al. (2008) proposed a novel protocol of MPTP nigrostriatal lesion to produce long-lasting and progressive loss of nigrostriatal dopaminergic neurons in male Wistar rats. Three days intervals were chosen considering the plasticity of the dopaminergic system in terms of the locomotor impairments inflicted by a single intranigral MPTP administration [66]. Another approach consisted of a 28-day treatment of MPP+ infused into the left cerebral ventricle via osmotic mini-pumps. The $35 \%$ or $65 \%$ loss of tyrosine hydroxylase positive neurons and Lewy-like pathology were observed in substantia nigra of male Sprague-Dawley rats. This model of progressive neurodegeneration of nigrostriatal dopamine neurons might be useful for studying neuroprotective therapeutic agents for PD [67].

Rojo, et al. (2006) recently reported that male C57BL/6 mice receiving daily intranasal inoculations with MPTP for 30 days developed motor deficits that correlated with depletion of striatal dopamine levels (up to $20 \%$ of controls) and a loss of tyrosine hydroxylase and dopamine transporter immunoreactivity in the substantia nigra and striatum [68]. Predinger, et al. (2006) have demonstrated that a single intranasal infusion of MPTP produced progressive signs of PD such as olfactory and cognitive impairments as well as motor disfunction in male Wistar rats [69]. Predinger et al. (2010) have also reported that most of the impairments presented by male C57BL/6 mice infused with a single intranasal administration of MPTP were similar to those observed during the early phase of $\mathrm{PD}$ when a moderate loss of nigral dopamine neurons results in olfactory and memory deficits with no major motor impairments. The levels of tyrosine hydroxylase were decreased in the olfactory bulb, striatum and substantia nigra by means of apoptotic mechanisms, and dopamine concentration was reduced in different brain structures (olfactory bulb, striatum, prefrontal cortex, but not in the hippocampus) [70]. Indeed, the nasal mucosa exhibit a large surface area directly exposed to environment chemicals, with high total blood flow, avoidance of first-pass metabolism and a weak blood-brain barrier. Only a few studies have addressed the possibility that neurotoxins such as MPTP could damage the basal ganglia following intranasal absorption [68-72]. These findings reinforce the hypothesis that the olfactory system represents a particularly sensitive route for the transport of neurotoxins into the CNS, closely related to 
the aetiology of $\mathrm{PD}[12]$.

Muthian et al. (2010) hypothesised that toxic substances are involved in the generation of idiopathic PD by inducing in early life „a sensitising stage“ and next, in adults, „a precipitating stage“. In their model, pregnant C57BL/6 mice were treated with MPTP administered intraperitoneally during gestation days 8-12 to target the emerging foetal nigrostriatal dopamine neurons. For the precipitating stage, the 3-months old offsprings were administered MPTP for 7 days, to simulate the changes that occur during ageing. Offsprings exposed to prenatal MPTP showed lower birth weights but eventually recovered. The postnatal MPTP administration was more potent in the prenatal MPTP-exposed offsprings. The severe toxicity caused by the postnatal MPTP challenge in the prenatal MPTP-exposed offsprings might represent the precipitating or inducing stage. The authors suggested that some cases of idiopathic PD may have a foetal basis in which early nigrostriatal impairments occurred and PD symptoms were precipitated later by deteriorating changes in the nigrostriatum that would not caused symptoms in individuals with normal nigrostriatal system. The study identified another possibility to explore and apply as a new animal MPTP-realted model for PD [73].

The discovery of mutations associated with familial forms of PD, including alpha-synuclein, Parkin, DJ-1, ubiquitin C-terminal hydrolase L1 T (UCHL1), PTEN-induced putative kinase 1 (PINK1) and Leucine-rich repeat kinase (LRRK2), has led to the generation of genetic mouse models of parkinsonism. In comparison with neurotoxin-based models, the genetic models are at early stages of behavioural and pharmacological characterisation, and especially the phenotypical characterisation of non-motor symptoms characteristic for the early and prodromal stage of PD remains an emerging area of research. In sporadic PD, several genes are likely to be altered, hence monogenic models are expected to be less successful than toxin-induced ones, but when used in combination should be even more beneficial and might allow to model the complete PD phenotype better [74,75]. And indeed, idiopathic (sporadic) PD is believed to be a multifactorial disorder, caused by the interaction between environmental (such as pesticide exposure) and genetic factors [26,27].

The exposure of PINK1 heterozygous knockout mice to low doses of rotenone, a mitochondrial complex I inhibitor, was not sufficient to significantly alter mitochondrial integrity and ATP production but it caused severe impairment of long-term plasticity at corticostriatal synapses [76]. A 3-week treatment with low doses of paraquat, one of the most popular herbicides, induced neither neurodegeneration in the substantia nigra nor altered the basic electrophysiological properties of both nigral and striatal neurons in PINK1 heterozygous mice. However, paraquat exposure caused complete failure of both longterm potentiation and long-term depression at corticostriatal synapses, which demonstrate that the exposure of PINK1 heterozygous mice to low doses of paraquat may exacerbate the initial breakdown of synaptic function typical for the early stage of the neurodegenerative process [77]. In transgenic mice with the A53T mutation overexpressing human alpha-synuclein, exposure to rotenone over a 35-day period resulted in decreased spontaneous locomotor movement and increased cytoplasmic alpha-synuclein expression. The mitochondrial Parkinson's-associated PTEN-induced kinase 1 protein levels were also increased in transgenic mouse brain after rotenone treatment but there was no change in brain dopamine levels or nigrostriatal cell loss [78].

More recently, another approach has been used to couple genetic manipulation and neurotoxins. Stereotactic unilateral viral delivery, using adeno-associated virus (AAV) vectors, of alpha-synuclein into the substantia nigra of male Sprague-Dawley rats was followed by 4-weeks subcutaneous exposure to rotenone via osmotic mini-pumps, causing motor dysfunction, nigrostriatal neurodegeneration and a-synucleinopathy to an extent that was greater than the impact of either insult alone [79]. Viruses have also been used to deliver short hairpin RNA (shRNA) to obtain an in vivo gene knockdown targeting SNCA transcript in adult male Lewis rats. The authors inhibited expression of endogenous alpha-synuclein in the rat substantia nigra through viral (AAV vectors) delivery of shRNA. Interestingly, knockdown of alpha-synuclein by $35 \%$ neither affected motor function nor caused degeneration of nigral dopaminergic neurons in control rats. However, motor deficits observed in rotenone-treated rats were significantly reduced contralateral to alpha-synuclein knockdown, suggesting that alpha-synuclein may modulate cellular susceptibility to external stressors [80].

These preliminary data highlight the relevance of such mixed models, confirming their validity and suggesting that such an experimental setting may be useful for future testing of neuroprotective and possibly disease-modifying therapeutic approaches [81].

Besides symptoms particularly attributable to pathologic changes in the nervous system many of them represent adverse effects of the gold standard medication in PD, namely L-DOPA, designed to replenish the loss of dopamine from dopaminergic neurons. In advanced PD L-DOPA cannot not effectively replenish dopamine because few dopaminergic neurons remain in the nigrostriatal pathway. The pathogenic effects of L-DOPA has been well documented, however, the mechanisms of action of L-DOPA is not entirely clear. Dopamine- and L-DOPAinduced neurotoxicity mediated by the generation of free radicals has been reported in damaged neurons in vitro and in vivo [82-84]. It was also demonstrated that repeated administration of L-DOPA increased lipid peroxidation in the striatum of parkinsonian mice lesioned by intracerebroventricular injection of 6-OHDA [83]. According to De Deurwaerdère et al. (2016), L-DOPA is principally transformed into dopamine in neurons yet, with a more important role for serotonergic than dopaminergic projections, as well as marked (probably indirect) influence upon cholinergic, GABAergic and glutamatergic neurons. L-DOPA may exert a complex pattern of neurochemical effects of much greater scope that striatal transformation into dopamine in spared dopaminergic neurons. Their further experimental and clinical clarification should help to improve both L-DOPA-based and novel strategies for controlling the motor and other, especially psychiatric, symptoms of PD [85].

Since dopamine and L-DOPA quinones may irreversibly alter protein function through the formation of 5-cysteinyl-catechols on the proteins, aminochrome was proposed as another preclinical model of PD [86-92]. Aminochrome is one of the o-quinones (the most stable o-quinone) formed during dopamine oxidation to neuromelanin and it has been found to induce mitochondrial dysfunction, formation of neurotoxic alpha-synuclein oligomers, oxidative stress, dysfunction of protein degradation of both proteasomal and lisosomal systems, endoplasmic reticulum stress [90-95]. Unilateral injection of aminochrome into striatum of Sprague-Dawley rats induced a progressive contralateral behaviour without loss of nigrostriatal dopaminergic neurons. The level of dopamine significantly decreased while the GABA level significantly increased [96]. Aminochrome is neurotoxic when it forms adducts with proteins or when reduced by flavoenzymes. However, there are two enzymes that prevent from aminochrome neurotoxicity: DT-diaphorase prevents aminochrome- 
induced cell death, mitochondrial dysfunction, oxidative stress, protein degradation dysfunction of both proteasomal and lysosomal systems together with formation of alpha-synuclein neurotoxic oligomers, while glutathione transferase M2-2 (GSTM2) catalyses the glutathione conjugation of both aminochrome and its precursor (dopamine o-quinone). Therefore, DT-diaphorase or GSTM2 knockouts injected with aminochrome might also serve as a new preclinical model to study both PD patomechanisms and to develop new antiparkinsonian drugs [89-91,96].

\section{Clinical trials related to early Parkinson's disease}

The actual treatment of PD is based on dopaminergic and anticholinergic compounds. Both the academia and the pharmaceutical industry have failed to find new compounds to stop or slow down the progression of the disease. Recently, numerous successful preclinical studies of potentially neuroprotective or disease modifying agents have also failed to translate their positive results to clinical studies, for instance: caffeine, coenzyme Q, creatine, estrogen, ganglioside, minocycline, nicotine, ubiquinone [97,99-100]. The lack of understanding regarding the pathogenesis of $\mathrm{PD}$, inaccurate animal models, limitations in trial design, insensitive endpoints/outcome measures of clinical trials, the lack of validated biomarkers and the suboptimal patient population choice for clinical trials have been enumerated as the significant obstacles that continue to impede the neuroprotective and antiparkinsonian drug development. Animal models of PD have undoubtedly led to great steps forward in the treatment of the motor symptoms and drugrelated complications of $\mathrm{PD}$, but it is too early to judge whether they might be successful in aiding the development of disease modifying or neuroprotective strategies [97]. Any data coming from animal studies should be carefully evaluated prior to generalisation, because of different experimental settings and confounding factors, such as routes of neurotoxins' administration, animal species and strains, chemical purity of administered compounds as well as different antibodies used in detection of Lewy-like pathology and other patomorphological changes [98].

Although the clinical research is ongoing, there are no validated and sensitive biomarkers to diagnose PD and monitor response to therapeutic interventions [97]. The Parkinson's Progression Markers Initiative has published encouraging results showing that levels of CSF A $\beta 1-42, T-t a u, P-t a u 181$ and $\alpha$-synuclein have prognostic and diagnostic potential in early stage $\mathrm{PD}$, with lower levels seen in $\mathrm{PD}$ compared with healthy controls [101]. There is also an increasing research interest in screening individuals for prodromal $\mathrm{PD}$, based on the symptoms (including loss of sense of smell, constipation, rapid eye movement sleep behaviour disorder and mood changes), along with dopamine transporter single-photon emission computed tomography scanning. The non-motor symptoms alone have insufficient specificity to identify the population at risk of developing $\mathrm{PD}$, before neurodegeneration progresses beyond the reach of any possible neuroprotective agent and before significant clinical symptoms occur [97,102].

\section{Conclusions and future directions}

Unfortunately, our understanding of the critical molecular events causing neurodegeneration in PD is limited and consequently there is little progress in pharmacotherapy of $\mathrm{PD}$, especially to interfere with the disease progression. The genuine complexity of $\mathrm{PD}$ as a syndrome with multiple aetiologies should be kept in the spotlight to ensure progress in the field. Thus, it seems logical to stress the importance of the ability to diagnose potential Parkinsonian patients accurately and instantly. The precise understanding of the changes in the disease course in relation to treatment effects and patient-level factors should warrant the proper design and efficiency of future preclinical studies. For the time being, the knowledge regarding Parkinson's disease should be primarily transferred from patients to animal models, if we want to effectively design not only the treatment to stop or slow down the disease but more importantly preventive strategies.

\section{Acknowledgments, funding and disclosures}

This study was funded by the Jagiellonian University Medical College Statutory Grant for Young Scientists (K/DSC/002098).

\section{References}

1. Parkinson J (2002) An essay on the shaking palsy. 1817. J Neuropsychiatry Clin Neurosci 14: 223-236. [Crossref]

2. De Rijk MC, Launer LJ, Berger K, Breteler MM, Dartigues JF, et al. (2000) Prevalence of Parkinson's disease in Europe: A collaborative study of population-based cohorts. Neurologic Diseases in the Elderly Research Group. Neurology 54: S21-S23. [Crossref]

3. Kompoliti K (2003) Estrogen and Parkinson's disease. Front Biosci 8: s391-400. [Crossref]

4. Wolters EC, van Laar T, Berendse HW (2010) Parkinsonism and Related Disorders. Amsterdam: $3^{\text {rd }}$ edition. VU University Press. 143-159.

5. Pfeiffer RF (2011) Gastrointestinal dysfunction in Parkinson's disease. Parkinsonism Relat Disord 17: 10-15. [Crossref]

6. Rodriguez-Oroz MC, Jahanshahi M, Krack P, Litvan I, Macias R, et al. (2009) Initia clinical manifestations of Parkinson's disease: features and pathophysiological mechanisms. Lancet Neurol 8: 1128-1139. [Crossref]

7. Wolters EC, Francot C, Bergmans P, Winogrodzka A, Booij J, et al. (2000) Preclinica (premotor) Parkinson's disease. J Neurol 247 Suppl 2: II103-109. [Crossref]

8. Wolters ECh, Braak H (2006) Parkinson's disease: premotor clinico-pathologica correlations. J Neural Transm Suppl 309-319. [Crossref]

9. Zlotnik Y, Balash Y, Korczyn AD, Giladi N, Gurevich T (2015) Disorders of the oral cavity in Parkinson's disease and parkinsonian syndromes. Parkinsons Dis 2015: 379482. [Crossref]

10. Chaudhuri KR, Yates L, Martinez-Martin P (2005) The non-motor symptom complex of Parkinson's disease: a comprehensive assessment is essential. Curr Neurol Neurosci Rep 5: 275-283. [Crossref]

11. Gallagher DA, Lees AJ, Schrag A (2010) What are the most important nonmotor symptoms in patients with Parkinson's disease and are we missing them? Mov Disord 25: 2493-2500. [Crossref]

12. Del Tredici K, Braak H (2016) Review: Sporadic Parkinson's disease: developmen and distribution of $\hat{\mathrm{I}} \pm$-synuclein pathology. Neuropathol Appl Neurobiol 42: 33-50. [Crossref]

13. Jellinger KA (2012) Neuropathology of sporadic Parkinson's disease: evaluation and changes of concepts. Mov Disord 27: 8-30. [Crossref]

14. Uversky VN, Eliezer D (2009) Biophysics of Parkinson's disease: structure and aggregation of alpha-synuclein. Curr Protein Pept Sci 10: 483-499. [Crossref]

15. Gibb WR, Lees AJ (1988) The relevance of the Lewy body to the pathogenesis of idiopathic Parkinson's disease. J Neurol Neurosurg Psychiatry 51: 745-752. [Crossref]

16. Goedert M, Spillantini MG, Del Tredici K, Braak H (2013) 100 years of Lewy pathology. Nat Rev Neurol 9: 13-24. [Crossref]

17. Villalba RM, Mathai A, Smith Y2 (2015) Morphological changes of glutamatergic synapses in animal models of Parkinson's disease. Front Neuroanat 9: 117. [Crossref]

18. Finlay C, Duty S (2014) Therapeutic potential of targeting glutamate receptors in Parkinson's disease. J Neural Transm (Vienna) 121: 861-880. [Crossref]

19. Beaudoin-Gobert M, Epinat J, Météreau E, Duperrier S, Neumane S, et al. (2015) Behavioural impact of a double dopaminergic and serotonergic lesion in the non-human primate. Brain 138: 2632-2647. [Crossref]

20. Beach TG, Adler CH, Sue LI, Vedders L, Lue L, et al. (2010) Multi-organ distribution of phosphorylated alpha-synuclein histopathology in subjects with Lewy body disorders. Acta Neuropathol 119: 689-702. [Crossref] 
21. Dickson DW, Braak H, Duda JE, Duyckaerts C, Gasser T, et al. (2009) Neuropathological assessment of Parkinson's disease: refining the diagnostic criteria. Lancet Neurol 8 : 1150-1157. [Crossref]

22. Dickson DW, Fujishiro H, Orr C, DelleDonne A, Josephs KA, et al. (2009) Neuropathology of non-motor features of Parkinson disease. Parkinsonism Relat Disord 15 Suppl 3: S1-5. [Crossref]

23. Lang AE, Obeso JA (2004) Challenges in Parkinson's disease: restoration of the nigrostriatal dopamine system is not enough. Lancet Neurol 3: 309-316. [Crossref]

24. Dauer W, Przedborski S (2003) Parkinson's disease: mechanisms and models. Neuron 39: 889-909. [Crossref]

25. Hirsch EC, Hunot S (2009) Neuroinflammation in Parkinson's disease: a target for neuroprotection? Lancet Neurol 8: 382-397. [Crossref]

26. Le W, Sayana P, Jankovic J (2014) Animal models of Parkinson's disease: a gateway to therapeutics? Neurotherapeutics 11: 92-110. [Crossref]

27. Pan-Montojo F, Reichmann H2 (2014) Considerations on the role of environmental toxins in idiopathic Parkinson's disease pathophysiology. Transl Neurodegener 3: 10. [Crossref]

28. Emborg ME (2004) Evaluation of animal models of Parkinson's disease for neuroprotective strategies. $J$ Neurosci Methods 139: 121-143. [Crossref]

29. Johnson ME, Bobrovskaya L (2015) An update on the rotenone models of Parkinson's disease: their ability to reproduce the features of clinical disease and model geneenvironment interactions. Neurotoxicology 46: 101-116. [Crossref]

30. Benabid AL, Chabardes S, Torres N, Piallat B, Krack P, et al. (2009) Functional neurosurgery for movement disorders: a historical perspective. Prog Brain Res 175: 379-391. [Crossref]

31. Blandini F, Armentero MT (2012) Animal models of Parkinson's disease. FEBS J 279: 1156-1166. [Crossref]

32. Doty RL, Stern MB, Pfeiffer C, Gollomp SM, Hurtig HI (1992) Bilateral olfactory dysfunction in early stage treated and untreated idiopathic Parkinson's disease. J Neuro Neurosurg Psychiatry 55: 138-142. [Crossref]

33. Doty RL (2012) Olfaction in Parkinson's disease and related disorders. Neurobiol Dis 46: 527-552. [Crossref]

34. Cersosimo MG, Benarroch EE (2012) Autonomic involvement in Parkinson's disease: pathology, pathophysiology, clinical features and possible peripheral biomarkers. $J$ Neurol Sci 313: 57-63. [Crossref]

35. Fifel K, Piggins H, Deboer T (2016) Modeling sleep alterations in Parkinson's disease: How close are we to valid translational animal models? Sleep Med Rev 25: 95-111. [Crossref]

36. Abbott RD, Ross GW, White LR, Tanner CM, Masaki KH, et al. (2005) Excessive daytime sleepiness and subsequent development of Parkinson disease. Neurology 65: 1442-1446. [Crossref]

37. Arnulf I, Konofal E, Merino-Andreu M, Houeto JL, Mesnage V, et al. (2002) Parkinson's disease and sleepiness: an integral part of PD. Neurology 58: 1019-1024. [Crossref]

38. McDowell KA, Hadjimarkou MM, Viechweg S, Rose AE, Clark SM, et al. (2010) Sleep alterations in an environmental neurotoxin-induced model of parkinsonism. Exp Neurol 226: 84-89. [Crossref]

39. Prediger RD, Matheus FC, Schwarzbold ML, Lima MM, Vital MA (2012) Anxiety in Parkinson's disease: a critical review of experimental and clinical studies. Neuropharmacology 62: 115-124. [Crossref]

40. Tolosa E, Compta Y, Gaig C (2007) The premotor phase of Parkinson's disease. Parkinsonism Relat Disord 13 Suppl: S2-7. [Crossref]

41. Chaudhuri KR, Healy DG, Schapira AH; National Institute for Clinical Excellence (2006) Non-motor symptoms of Parkinson's disease: diagnosis and management. Lancet Neurol 5: 235-245. [Crossref]

42. Ziemssen T, Reichmann H (2007) Non-motor dysfunction in Parkinson's disease. Parkinsonism Relat Disord 13: 323-332. [Crossref]

43. Braak H, Ghebremedhin E, Rüb U, Bratzke H, Del Tredici K (2004) Stages in the development of Parkinson's disease-related pathology. Cell Tissue Res 318: 121-134. [Crossref]

44. Gonera EG, van’t Hof M, Berger HJ, van Weel C, Horstink MW (1997) Symptoms and duration of the prodromal phase in Parkinson's disease. Mov Disord 12: 871-876. [Crossref]

45. Gerlach M, Maetzler W, Broich K, Hampel H, Rems L, et al. (2012) Biomarker candidates of neurodegeneration in Parkinson's disease for the evaluation of diseasemodifying therapeutics. J Neural Transm (Vienna) 119: 39-52. [Crossref]

46. McDowell K, Chesselet MF (2012) Animal models of the non-motor features of Parkinson's disease. Neurobiol Dis 46: 597-606. [Crossref]

47. Przedborski S, Jackson-Lewis V, Naini AB, Jakowec M, Petzinger G, et al. (2001) The parkinsonian toxin 1-methyl-4-phenyl-1,2,3,6-tetrahydropyridine (MPTP): a technical review of its utility and safety. $J$ Neurochem 76: 1265-1274. [Crossref]

48. Lane EL, Cheetham SC, Jenner P (2006) Does contraversive circling in the 6-OHDAlesioned rat indicate an ability to induce motor complications as well as therapeutic effects in Parkinson's disease? Exp Neurol 197: 284-290. [Crossref]

49. Thiruchelvam M, Richfield EK, Baggs RB, Tank AW, Cory-Slechta DA (2000) The nigrostriatal dopaminergic system as a preferential target of repeated exposures to combined paraquat and maneb: implications for Parkinson's disease. J Neurosci 20: 9207-9214. [Crossref]

50. Beal MF (2001) Experimental models of Parkinson's disease. Nat Rev Neurosci 2: 325 334. [Crossref]

51. Betarbet R, Sherer TB, Greenamyre JT (2002) Animal models of Parkinson's disease. Bioessays 24: 308-318. [Crossref]

52. Meredith GE, Sonsalla PK, Chesselet MF (2008) Animal models of Parkinson's disease progression. Acta Neuropathol 115: 385-398. [Crossref]

53. Potashkin JA, Blume SR, Runkle NK (2010) Limitations of animal models of Parkinson's disease. Parkinsons Dis 2011: 658083. [Crossref]

54. Tieu K (2011) A guide to neurotoxic animal models of Parkinson's disease. Cold Spring Harb Perspect Med 1: a009316. [Crossref]

55. Betarbet R, Sherer TB, MacKenzie G, Garcia-Osuna M, Panov AV, et al. (2000) Chronic systemic pesticide exposure reproduces features of Parkinson's disease. Nat Neurosci 3: 1301-1306. [Crossref]

56. Blesa J, Phani S, Jackson-Lewis V, Przedborski S (2012) Classic and new animal models of Parkinson's disease. J Biomed Biotechnol 2012: 845618. [Crossref]

57. Kurnik M, Gil K, Gajda M, Thor P, Bugajski A (2015) Neuropathic alterations of the myenteric plexus neurons following subacute intraperitoneal administration of salsolinol. Folia Histochem Cytobiol 53: 49-61.

58. Kurnik M, Gil K, Bugajski A, Bujak-Gizycka B, Madej J, et al. (2012) The influence of salsolinol on basic rat metabolism. Folia Med Cracov 52: 5-20. [Crossref]

59. Duty S, Jenner P (2011) Animal models of Parkinson's disease: a source of novel treatments and clues to the cause of the disease. Br J Pharmacol 164: 1357-1391. [Crossref]

60. Da Cunha C, Angellucci MEM, Canteras NS, Wonnacott S, Takahashi RN (2002) The lesion of the rat substantia nigra pars compacta dopaminergic neurons as a model for Parkinson's disease memory disabilities. Cell Mol Neurobiol 22: 227-37. [Crossref]

61. Ferro MM, Bellissimo MI, Anselmo-Franci JA, Angellucci MEM, Canteras NS, et al. (2005) Comparison of bilaterally 6-OHDA- and MPTP-lesioned rats as models of early phase of Parkinson's disease: histological, neurochemical, motor and memory alterations. J Neurosci Methods 148: 78-87. [Crossref]

62. Lima MMS, Reksidler AB, Zanata SM, Machado HB, Tufik S, et al. (2006) Different parkinsonism models produce a time-dependent induction of COX-2 in the substantia nigra of rats. Brain Res 1101: 117-125. [Crossref]

63. Miyoshi E, Wietzikoski S, Camplessei M, Silveira R, Takahashi RN, et al. (2002) Impaired learning in a spatial working memory version and in a cued version of the water maze in rats with MPTP-induced nigral lesion. Brain Res Bull 58: 41-47. [Crossref]

64. Perry JC, Hipólide DC, Tufik S, Martins RD, Da Cunha C, et al. (2005) Intra-nigral MPTP lesion in rats: behavioral and autoradiography studies. Exp Neurol 195: 322 329. [Crossref]

65. Reksidler AB, Lima MM, Zanata SM, Machado HB, da Cunha C, et al. (2007) The COX-2 inhibitor parecoxib produces neuroprotective effects in MPTP-lesioned rats Eur J Pharmacol 560: 163-175. [Crossref]

66. Reksidler AB, Lima MM, Dombrowski P, Andersen ML, Zanata SM, et al. (2008) Repeated intranigral MPTP administration: a new protocol of prolonged locomotor 
impairment mimicking Parkinson's disease. J Neurosci Methods 167: 268-77. [Crossref]

67. Yazdani U, German DC, Liang CL, Manzino L, Sonsalla PK, et al. (2006) Rat model of Parkinson's disease: chronic central delivery of 1-methyl-4-phenylpyridinium (MPP+). Exp Neurol 200: 172-183. [Crossref]

68. Rojo AI, Montero C, Salazar M, Close RM, Fernández-Ruiz J, et al. (2006) Persistent penetration of MPTP through the nasal route induces Parkinson's disease in mice. Eur J Neurosci 24: 1874-1884. [Crossref]

69. Prediger RD, Aguiar AS Jr, Rojas-Mayorquin AE, Figueiredo CP, Matheus FC, et al. (2010) Single intranasal administration of 1-methyl-4-phenyl-1,2,3,6tetrahydropyridine in C57BL/6 mice models early preclinical phase of Parkinson's disease. Neurotox Res 17: 114-29. [Crossref]

70. Prediger RD, Batista LC, Medeiros R, Pandolfo P, Florio JC, et al. (2006) The risk is in the air: Intranasal administration of MPTP to rats reproducing clinical features of Parkinson's disease. Exp Neurol 202: 391-403. [Crossref]

71. Dluzen DE, Kefalas G (1996) The effects of intranasal infusion of 1-methyl-4phenyl-1,2,3,6-tetrahydropyridine (MPTP) upon catecholamine concentrations within olfactory bulbs and corpus striatum of male mice. Brain Res 741: 215-219. [Crossref]

72. Tristão FS, Amar M, Latrous I, Del-Bel EA, Prediger RD, et al. (2014) Evaluation of nigrostriatal neurodegeneration and neuroinflammation following repeated intranasal 1-methyl-4-phenyl-1,2,3,6-tetrahydropyridine (MPTP) administration in mice, an experimental model of Parkinson's disease. Neurotox Res 25: 24-32. [Crossref]

73. Muthian G, Mackey V, King J, Charlton CG (2010) Modeling a sensitization stage and a precipitation stage for Parkinson's disease using prenatal and postnatal 1-methyl4-phenyl-1,2,3,6-tetrahydropyridine administration. Neuroscience 169: 1085-93. [Crossref]

74. Dawson TM, Ko HS, Dawson VL (2010) Genetic animal models of Parkinson's disease. Neuron 66: 646-661. [Crossref]

75. Jagmag SA, Tripathi N, Shukla SD, Maiti S, Khurana S (2016) Evaluation of Models of Parkinson's Disease. Front Neurosci 9: 503. [Crossref]

76. Martella G, Madeo G, Maltese M, Vanni V, Puglisi F, et al . (2016) Exposure to lowdose rotenone precipitates synaptic plasticity alterations in PINK1 heterozygous knockout mice. Neurobiol Dis 91: 21-36. [Crossref]

77. Nisticò R, Mehdawy B, Piccirilli S, Mercuri N (2011) Paraquat- and rotenone-induced models of Parkinson's disease. Int J Immunopathol Pharmacol 24: 313-322. [Crossref]

78. George S, Mok SS, Nurjono M, et al. (2010) $\alpha$-Synuclein transgenic mice revea compensatory increases in Parkinson's disease-associated proteins DJ-1 and parkin and have enhanced alpha-synuclein and PINK1 levels after rotenone treatment. $J$ Mol Neurosci 42: 243-254. [Crossref]

79. Mulcahy P, O’Doherty A, Paucard A, O’Brien T, Kirik D, et al. (2013) The behavioural and neuropathological impact of intranigral AAV-a-synuclein is exacerbated by systemic infusion of the Parkinson's disease-associated pesticide, rotenone, in rats. Behav Brain Res 243: 6-15. [Crossref]

80. Zharikov AD, Cannon JR, Tapias V, Bai Q, Horowitz MP, et al. (2015) shRNA targeting $\hat{\mathrm{I}} \pm$-synuclein prevents neurodegeneration in a Parkinson's disease model. $J$ Clin Invest 125: 2721-2735. [Crossref]

81. Schirinzi T, Madeo G, Martella G, Maltese M, et al. (2016) Early synaptic dysfunction in Parkinson's disease: Insights from animal models. Mov Disord 31: 802-813. [Crossref]

82. Cadet JL, Brannock C (1998) Free radicals and the pathobiology of brain dopamine systems. Neurochem Int 32: 117-131. [Crossref]

83. Ogawa N, Edamatsu R, Mizukawa K, Asanuma M, Kohno M, et al. (1993) Degeneration of dopaminergic neurons and free radicals. Possible participation of levodopa. $A d v$ Neurol 60: 242-250. [Crossref]
84. Asanuma M, Miyazaki I, Ogawa N (2003) Dopamine- or L-DOPA-induced neurotoxicity: the role of dopamine quinone formation and tyrosinase in a model of Parkinson's disease. Neurotox Res 5: 165-176. [Crossref]

85. De Deurwaerdère P, Di Giovanni G, Millan MJ (2016) Expanding the repertoire of L-DOPA's actions: A comprehensive review of its functional neurochemistry. Prog Neurobiol . [Crossref]

86. Miyazaki I, Asanuma M (2008) Dopaminergic neuron-specific oxidative stress caused by dopamine itself. Acta Med Okayama 62: 141-150. [Crossref]

87. Segura-Aguilar J, Paris I, Muñoz P, Ferrari E, Zecca L, et al. (2014) Protective and toxic roles of dopamine in Parkinson's disease. J Neurochem 129: 898-915. [Crossref]

88. Segura-Aguilar J, Muñoz P, Paris I (2015). Aminochrome as new preclinical model to find new pharmacological treatment that stop the development of Parkinson's disease. Curr Med Chem 23: 346-359. [Crossref]

89. Muñoz P, Paris I, Segura-Aguilar J (2016) Corrigendum: Commentary: Evaluation of Models of Parkinson's Disease. Front Neurosci 10: 320. [Crossref]

90. Aguirre P, Urrutia P, Tapia V, Villa M, Paris I, et al. (2012). The dopamine metabolite aminochrome inhibits mitochondrial complex I and modifies the expression of iron transporters DMT1 and FPN1. Biometals 25: 795-803. [Crossref]

91. Muñoz P, Cardenas S, Huenchuguala S, Briceño A, Couve E, et al. (2015) DTDiaphorase Prevents Aminochrome-Induced Alpha-Synuclein Oligomer Formation and Neurotoxicity. Toxicol Sci 145: 37-47. [Crossref]

92. Arriagada C, Paris I, Sanchez de las Matas MJ, Martinez-Alvarado P, Cardenas S, et al (2004) On the neurotoxicity mechanism of leukoaminochrome o-semiquinone radical derived from dopamine oxidation: mitochondria damage, necrosis, and hydroxyl radical formation. Neurobiol Dis 16: 468-477. [Crossref]

93. Zafar KS, Siegel D, Ross D (2006) A potential role for cyclized quinones derived from dopamine, DOPA, and 3,4-dihydroxyphenylacetic acid in proteasomal inhibition. $M o l$ Pharmacol 70:1079-1086. [Crossref]

94. Huenchuguala S, Muñoz P, Zavala P, Villa M, Cuevas C, et al. (2014) Glutathione transferase mu 2 protects glioblastoma cells against aminochrome toxicity by preventing autophagy and lysosome dysfunction. Autophagy 10: 618-630. [Crossref]

95. Xiong, R., Siegel, D., and Ross, D. (2014). Quinone-induced protein handling changes implications for major protein handling systems in quinone-mediated toxicity. Toxicol Appl Pharmacol 280: 285-295. [Crossref]

96. Herrera A, Muñoz P, Paris I, et al. (2016) Aminochrome induces dopaminergic neuronal dysfunction: a new animal model for Parkinson's disease. Cell Mol Life Sci 73: 3583 3597. [Crossref]

97. Athauda D, Foltynie T (2015) The ongoing pursuit of neuroprotective therapies in Parkinson disease. Nat Rev Neurol 11: 25-40. [Crossref]

98. Kurnik M, Thor P (2015) The non-motor complications in Parkinson's disease - what can we learn from animal models? Folia Med Cracov 55: 69-84. [Crossref]

99. Park A, Stacy M2 (2015) Disease-Modifying Drugs in Parkinson's Disease. Drugs 75 2065-2071. [Crossref]

100. Olanow CW, Bartus RT, Volpicelli-Daley LA, Kordower JH (2015) Trophic factors for Parkinson's disease: To live or let die. Mov Disord 30: 1715-1724. [Crossref]

101. Kang JH, Irwin DJ, Chen-Plotkin AS, Siderowf A, Caspell C, et al. (2013) Association of cerebrospinal fluid $\hat{\mathrm{I}}^{2}$-amyloid 1-42, T-tau, P-tau181, and $\hat{\mathrm{I}} \pm$-synuclein levels with clinical features of drug-naive patients with early Parkinson disease. JAMA Neurol 70: 1277-1287. [Crossref]

102. Mahlknecht P, Seppi K, Poewe W (2015) The Concept of Prodromal Parkinson's Disease. J Parkinsons Dis 5: 681-697. [Crossref]

Copyright: (C2016 Kurnik-Łucka M. This is an open-access article distributed under the terms of the Creative Commons Attribution License, which permits unrestricted use, distribution, and reproduction in any medium, provided the original author and source are credited. 